Revista Iberoamericana. Vol. LXIV, Núms. 182-183, Enero-Junio 1998; 219-228

\title{
AMÉRICA LATINA REINVENTADA: OCTAVIO PAZ E HAROLDO DE CAMPOS
}

\author{
POR \\ MARIA Esther MACIEL \\ Universidade Federal de Minas Gerais
}

\author{
Desler, tresler, contraler, \\ enlear-se nos ritmos da matéria, \\ no fora, ver o dentro e, no dentro, ofora, \\ navegar em direção às Indias \\ e descobrir a América.
}

Paulo Leminski

I

Foram muitos os poetas latino-americanos deste século que se empenharam em transformar suas obras - pela prática polivalente da criação, da reflexão crítica e da tradução- em uma espécie de ars combinatoria de signos culturais de tempos, tradições e espaços diversos. Cosmopolitas, enciclopédicos, tentaculares, contemporâneos de todas as idades poéticas, autores como Jorge Luis Borges, Octavio Paz, Julio Cortázar, Lezama Lima, Alfonso Reyes, Severo Sarduy, Mário de Andrade, Haroldo de Campos, dentre outros, souberam burlar as dicotomias entre universalismo e americanismo, identidade e alteridade, ruptura e tradição. Ao colocarem a América Latina no circuito planetário das trocas criativas, ao mesmo tempo que pensando teoricamente essa inserção, contribuíram para a abertura da cultura latino-americana ao influxo de outras culturas ocidentais e orientais, além de as inserirem no fluxo de uma universalidade também pluralizada e descentrada.

Não foi à toa que muitos deles elegeram metáforas cosmológicas para definir o trabalho textual. Borges, além de fazer de cada texto seu, como bem aponta Italo Calvino, um modelo ou um atributo do universo, vide a famosa "Biblioteca de Babel", dedicou-se ao tema mallarmeano do Grande Livro, espécie de "transenciclopédia" galáctica, soma infinita dos saberes possíveis. Lezama, com sua cosmovisão barroca, construiu um sistema poético fundado na proliferação de imagens, buscando inventar, através da linguagem, uma nova ordem universal. Paz, afeito à lógica analógica, não apenas converteu a expressão "signos em rotação" em uma chave de leitura de sua 
própria obra, como também criou poemas nos quais a identidade dissonante entre a página e o espaço estelar se coloca como base de sua construção, reeditando - só que agora sob o prisma da idéia de cisão-a a idéia secular do texto como duplo do universo. Metáfora essa que também norteia a vasta obra de Haroldo de Campos, criador do poema-crítico Galáxias, uma combinatória conversível de signos barrocos, assentado sobre a analogia do texto como viagem interestelar e vice-versa. Para não dizer de sua proposta de uma "história constelar" da literatura, que - resguardadas as diferençasmantém uma afinidade com a leitura feita por Paz dos signos em rotação da história da poesia moderna ocidental.

Essa tendência, detectável também - de certa maneira - em alguns autores do passado, como Sor Juana Inés de la Cruz, que além de ter transitado em campos interdisciplinares, fez do seu poema "Primero Sueño" uma alegoria da busca do conhecimento através do vôo vertiginoso da alma pelas esferas supralunares, é associada, por Severo Sarduy, em seus Ensayos generales sobre el barroco, a uma consciência neobarroca dos escritores de nosso continente. Estes, seduzidos pelos rumos cada vez mais intrincados da astronomia contemporânea, estariam reeditandode maneira diferente, porque sintonizada com uma outra concepção de cosmos-o empreendimento barroco de fazer do universo um desafio à imaginação. Para atestar suas proposições, o escritor cubano percorre todas as teorias cosmológicas pré e pósbarroco, até chegar às recentes teorias do big bang e da expansão do universo, que estariam alimentando a imaginação e a consciência de muitos autores do nosso tempo. ${ }^{1}$

Se, por um lado, a teoria analógica de Sarduy oferece uma maneira criativa de se lidar com a complexa diversidade de vários poetas e prosadores latino-americanos contemporâneos, sobretudo no que diz respeito à riqueza textual e à pluralidade cambiante de suas obras, poderíamos, por outro lado, a ela acrescentar uma outra constatação, de ordem mais cultural: a que se refere à abertura que a estética latinoamericana sempre manteve em relação ao outro, à habilidade que ela tem de incorporar o estranho, o estrangeiro. Tendência que, embora possa remontar ao século XVII , se evidencia de maneira mais explícita ao longo deste século.

Pode-se dizer que, se numa primeira instância o processo de assimilação de alteridades apresentou-se basicamente em relação à cultura européia, as rotas desse processo foram se alterando, na medida em que o interesse pelo "outro" se estendeu a outras tradições, advindas tanto do passado precolonial de cada país latino-americano, quanto das civilizações orientais ou das culturas ex-cêntricas do Ocidente. Do que resultou uma literatura híbrida e em descontínuo movimento rumo a uma identidade cada vez mais repleta de singularidades dissonantes. Literatura que, mesmo tendo entrado no fluxo acidentado porém sucessivo dos estilos de época surgidos na Europa, burla com a perspectiva linear do historicismo literário, por se configurar sempre como outra coisa, por extravasar os limites do paradigma e embaralhar as referências consagradas.

\footnotetext{
${ }^{1}$ Ver Sarduy.
} 
Não foi à toa que Lezama Lima usou, em seus apontamentos críticos sobre a literatura americana (não deixa de ser curioso que o poeta "latinize" também a América do Norte), a imagem carnavalizada do banquete, com o propósito de elucidar como essa literatura se constitui como uma rede, capaz de somar e recriar imagens residuais provenientes de outras tradições:

\begin{abstract}
No banquete literário, o americano vem cumprir a função daquele que realiza a prova maior. Depois das bandejas que trazem os assados, as frutas sorridentes e o costelame auroral do crustáceo, vem a perinha ostreira, como podia ter sido o confeito ou o creme para repassar com o azeite ou o bolinho que serve de intermediário entre o fogo e o estufado. O ocidental, treinado na gota do alambique, acrescenta a moagem da essência do café, trazido pela magia das culturas orientais, que oferece o deleite de algumas overturas à turca realizada por Mozart, ou a referência que já fizemos a algumas cantatas alegres em que se entretinha o majestoso divertimento bachiano. Era essa essência, uma espécie de ponto a mais na doçura do creme, um luxo ocidental que ampliava com essa gota oriental as variantes metafísicas do gosto. Mas a essa perfeição do banquete que leva a assimilação à cultura, corresponderia ao americano o primor inapelável, o rotundo ponto final da folha do tabaco. O americano trazia a esse refinamento do banquete ocidental o outro refinamento da natureza. Um terminar com um sabor de natureza, que recordava a primeira etapa anterior às transmutações do fogo. Com a natureza, que brinda um fumo, que traz o louvor e a oferenda essencial da evaporação (Lezama Lima, $A$ expressão 139).
\end{abstract}

Sem dúvida, uma analogia de feição antropofágica, que de certa maneira vem abalizar a proposição lezamiana de que o conjunto de imagens poéticas, literárias, de uma cultura não coincide necessariamente com essa cultura, embora com ela mantenha uma coincidência eventual, por nela estar inserido historicamente. Isso, pelo fato de o autor considerar que esse imaginário, além de ser criado pela vivência poética de um povo, recolhe, retém ou incorpora os restos de outros imaginários, configurando-se no caso específico da América - como "sumas críticas" realizadas graças à "voracidade" e ao "protoplasma incorporativo" do americano.

Tanto em Lezama como em Sarduy encontramos uma via alternativa, porque poética e não comprometida com os paradigmas teóricos cultuados, de se entender a complexidade híbrida e em movimento de nossa literatura. Ainda que tangenciando um certo transcendentalismo, essa via descortina criativamente questões sérias sobre os problemas de identidades e hibridismos culturais, hoje tão discutidos, sob o ângulo político-antropológico, pela crítica multicultural. Além de oferecer também subsídios indispensáveis para quem se dispõe a investigar a evidente propensão à pluralidade de autores contemporâneos que se dão, individualmente, a tarefa de converterem suas obras em um duplo diferencial do universo em expansão, ainda que nem todos possam ser tomados, na esteira de Sarduy, como neobarrocos de preceito.

É, portanto, sob o influxo dessa multiplicidade paradoxal trazida pelas teorias inventivas de Lezama e Sarduy, que pretendo rastrear comparativamente as obras de 
Octavio Paz e Haroldo de Campos, considerando que ambos, ao romper —cada um à sua maneira - com o caráter meramente dual do jogo cosmopolitismo e americanismo, Ocidente e Oriente, construíram, assim como os autores cubanos, uma imagem plural e descentrada de América Latina, na mesma proporção em que reinventaram o próprio conceito de "universalidade" (hoje tão em descrédito), ao não circunscrevê-lo ao território delimitado e canonizado da literatura ocidental de substrato europeu.

Movidos pela idéia de que o confronto e a assimilação da diferença configuramse como "um necessário exercício de autocrítica" (de Campos 255), Octavio Paz e Haroldo de Campos vêm problematizando, através da criação poética, da reflexão crítica e da prática tradutória, a rede de relações que compõe a literatura latinoamericana, em seu trânsito entre um cosmopolitismo sem fronteiras e um americanismo feito de matizes e rizomas.

Retomando uma questão que mobilizou muitos escritores latino-americanos do início do século e dialogando com outros que, como já vimos, extrapolaram o mero embate entre o particular e o universal, o nacional e o estrangeiro, ambos oferecem respostas também alternativas para a questão e discutem - sob o lume poético-a pluralidade híbrida da América Latina desta segunda metade do século. Octavio Paz, pela via analógica. Haroldo de Campos, pela via antropofágica.

A analogia, vista não como uma mera relação de semelhanças, mas como uma tensão (movida pelo jogo de afinidades e dissonâncias) entre os termos, vai nortear o pensamento e a obra do autor mexicano. Não a exclusiva identidade e nem a radical diferença. Mas o jogo, a relação. Fluxo e refluxo, conjunção e disjunção, ao mesmo tempo.

É a partir dessa lógica analógica que contém dentro de si mesma a idéia de cisão (chamada pelo autor de ironia) que o poeta mexicano vai construir o seu conceito de otredad (o reconhecer-se outro, sem deixar de ser o mesmo), onde as noções de identidade e alteridade mantêm uma relação dialógica e não excludente. Conceito esse, imprescindível para se compreender o problema do embate entre a cultura latinoamericana e o legado estrangeiro, na obra paziana. E ao qual se soma a idéia de tradução, compreendida em sua dupla face de repetição e ruptura, ou seja, em sua potencialidade de assegurar a continuidade de uma tradição, na mesma proporção em que rompe com ela e a transforma.

Paz considera tanto a criação quanto a leitura tarefas de tradução, uma vez que, para ele, criar é uma forma de ler as metáforas do mundo; e considerando que a leitura recria, modificando e continuando, ao mesmo tempo, essas imagens, pode ser também concebida como um exercício tradutório, procedimento repetido ad infinitum por escritores/leitores ao longo do tempo:

El juego de la analogía es infinito: el lector repite el gesto del poeta: la lectura es una traducción que convierte el poema del poeta en el poema del lector. La poética de la 
analogía consiste en concebir la creación literaria como una traducción; esa traducción es múltiple y nos enfrenta a esta paradoja: la pluralidad de autores (Paz, "Una forma ..."109).

Esse movimento é estendido, pelo poeta, a todos os campos culturais, à medida que considera o nosso século como "el siglo de las traducciones", não somente de textos, "sino de costumbres, religiones, danzas, artes eróticas y culinarias, modas y, en fin, de toda suerte de usos y prácticas" (Paz, "Canto móvil" 165). O que explica, portanto, o confronto paradoxal da literatura latino-americana deste século com a tradição central do Ocidente, visto também como uma experiência tradutória atravessada, simultaneamente, por uma aceitação e uma recusa. Aceitação, pelo fato de o latino-americano querer participar de uma cultura que, embora o exclua, também lhe pertence; e uma recusa, por ele lançar um olhar crítico sobre esse outro e buscar modificá-lo pelo viés da imaginação e do resgate de outras vozes culturais de tempos e territórios diferentes. No dizer do autor:

El latinoamericano es un ser que ha vivido en los suburbios de Occidente, en las afueras de la historia. Al mismo tiempo, se siente (y es) parte de una tradición que, hasta hace poco, lo desdeñaba. [...] Por eso cada poeta latinoamericano afirma con el mismo énfasis - habría que decir: con la misma exasperación - su originalidad latinoamericna y su ser como parte de una tradición universal. [...] Cada obra latinoamericana es una prolongación y una transgresión de Occidente (Paz, Pasión 69).

Ainda que Paz aponte, nos interstícios de sua fala, para uma suposta essência do latino-americano, que vai ser relativizada mais tarde (Paz, América 205), quando ele nega ser a América Latina uma substância e questione criticamente o termo "identidade" no singular, pode-se perceber, nessa citação, um olhar dialógico sobre o problema. Olhar que vai nortear a própria leitura que Paz vai fazer, no livro Los hijos del limo, da história da poesia moderna em seus múltiplos paradoxos.

O autor, ao assumir muitas vezes a sua condição de "sujeito metafórico", tal como postulou Lezama, vislumbra, nessa obra, a história da poesia moderna ocidental como um conjunto de signos em rotação, ou como diria Carlos Fuentes, uma "rede de circulações" (Fuentes 15), realizando, por isso, uma espécie de espacialização do tempo e colocando em coexistência sincronia e diacronia, cosmopolitismo e americanismo, Ocidente e Oriente. Sem deixar, contudo, de firmar para o leitor o seu ângulo privilegiado de enunciação: o de um poeta hispano-americano que, não obstante ou por isso mesmo, tem a desenvoltura para traçar o intrincado mapa desse conjunto poético em movimento, desde o romantismo alemão e inglês, entrelaçandoos a vários momentos e tendências poéticas que vão e vem da Europa à América Latina, destas ao mundo eslavo e à América do Norte, com algumas incursões na tradição oriental. Mesmo atento ao fio cronológico, ainda que para ele "la cronología, el 
sucederse las cosas unas detrás de otras, sea una relación aunque no la única ni la más importante" (Paz, "Una forma" 209), ele faz dessa história uma zona móvel de interações, com a nítida preocupação de evidenciar como cada tradição e cada tempo são traduções das demais. E nesse jogo de analogias, a literatura latino-americana (representada pelo próprio autor), tem uma participação ativa, pontual.

Esse procedimento se repete, de maneira diferente, em outras obras, como Conjunciones y disyunciones, onde uma teia metafórica é construída aos poucos pelo autor, à medida que vai discutindo os signos da história do mundo indo-europeu, contrapondo-os analogicamente às várias expressões da cultura oriental, como o hinduísmo, o taoísmo, o islamismo e as várias seç̧ões do Budismo. Ou como o livro Sor Juana o las trampas de la fe, onde uma autora mexicana do séc. XVII é revisitada à luz da "modernidade mais moderna", em meio a um complexo jogo analógico entre americanismo e cosmopolitismo, passado e presente, continuidade e descontinuidade.

Ao inserir a América Latina no concerto universal, Paz, longe de diluir as marcas diferenciais de nossa literatura em relação às outras, mostra que, exatamente, por estar ao mesmo tempo em sintonia e dissonância com as demais, ela sustenta a sua especificidade. Não uma especificidade uniforme, mas contraditória, pluralizada e em movimento. E é nesse sentido que a expressão "busca da identidade" soa-lhe imprópria, por considerar que o que chamamos identidade "no es una cosa que se pueda tener, perder o recobrar, tampoco es una sustancia ni una esencia"(Paz, Itinerário $205),{ }^{2}$ porque nela ressoam sempre as vozes diferenciais da otredad. Eétambém nesse sentido que o termo "universal" se desveste, sob suas considerações, da dimensão fechada, unitarista, que as antigas cosmologias e a estética clássica cunharam, mas que funciona até hoje como referência para o conceito. Isso, porque o que se depreende de sua obra é que ele toma a literatura universal mais ou menos como o que Sarduy chamou de "un estallido en el que los signos giran y se escapan hacia los límites del soporte sin que ninguna fórmula permita trazar sus líneas o seguir los mecanismos de su producción"(Sarduy 41). Um universo em cambio contínuo, que não pode ser apreendido em modelizações absolutas.

Sustentando-se de recorrentes imagens cosmológicas, tanto para definir ou infinitizar a sua concepção analógica de poesia, quanto para ler — sob uma perspectiva simultaneamente sincrônica e diacrônica - os signos em rotação da poesia moderna ocidental, Octavio Paz adota, em certa medida, a proposta de "história constelar" elaborada por Haroldo de Campos. Ou seja, uma história que entenda a tradição como "um constante e renovado questionar da diacronia pela sincronia" (Campos, $O$ seqüestro 63) e que evolua "por linhas tortas, por descontinuidades, por aparentes descaminhos" (Campos, Metalinguagem 260). E se digo em certa medida, é por pensar no caráter mais radical que atravessa as proposições do poeta-crítico brasileiro, notadamente mais pulverizante e mais comprometido com o que eu chamaria de uma lógica da ruptura.

${ }^{2}$ Ver também o ensaio "Nosotros: los otros". 
Se, assim como Paz, Campos privilegia o barroco em sua dimensão diferencial como uma referência para a modernidade estética latino-americana e problematiza dialogicamente, através da noção de jogo, as dicotomias entre universal e nacional, identidade e diferença, a maneira como ele lida com essas questões é distinta, por se sustentar não da "lei das correspondências universais", mas da noção oswaldiana de antropofagia, transformada agora em um conceito operacional. Sem, contudo, como já se pôde constatar, abrir mão de algumas metáforas de feição cosmológica como referências pontuais de suas leituras.

Pode-se dizer que, enquanto Paz relativiza a um só tempo as semelhanças e as diferenças de uma relação, Campos prioriza a força das diferenças, no processo que ele chama de devoração crítica, ou seja, a assimilação orgânica, por parte dos escritores brasileiros e hispano-americanos, do outro, do estrangeiro. Processo no qual o devorador tritura (destrói) o devorado, na mesma proporção em que o incopora e o modifica de maneira criativa. ${ }^{3}$ Inegavelmente, uma outra concepção de tradução, que guarda similitudes com a visão lezâmica e que não deixa também de se avizinhar da proposta de Paz, por conter implicitamente a idéia de "otredad", ainda que esvaziada da dimensão ontológica que atravessa os apontamentos pazianos sobre a questão.

É a partir dessa "razão antropofágica" que o poeta brasileiro constrói o seu conceito de "nacionalismo diferencial" e cria a proposta de uma "história constelar" da literatura brasileira, na qual o barroco aparece como uma "antitradição que passa pelos desvãos da historiografia universal" e que funciona como uma "não-origem" fundadora de nossa literatura. Ou seja, enquanto Paz trata o barroco hispano-americano como uma tradição feita de repetições e rupturas do modelo peninsular, Campos insere o barroco brasileiro (e, por extensão, o hispano-americano), numa zona de rupturas, por tomá-lo predominantemente sob a perspectiva da antropofagia, da desconstrução maxilar da tradição, optando por uma abordagem mais sincrônica que diacrônica.

Essa perspectiva atravessa toda a leitura haroldiana da literatura brasileira e hispano-americana, em seus momentos coloniais e poscoloniais, na medida em que ao escritor latino-americano é atribuída uma "lógica do terceiro excluído", "expropriatória e devorativa do ex-cêntrico, do descentrado" (Campos $O$ seqüestro 261), que o torna uma espécie de "tradutor diferencial da tradição". Assertiva esta que ganha, nas reflexões feitas pelo poeta brasileiro sobre os rumos da literatura contemporânea, uma dimensão mais complexa, porque pautada na idéia do que ele chama de "redevoração planetária", ou seja, da prática antropofágica elevada ao nível da transculturação recíproca entre Europa e América Latina. O que se deu, segundo ele, no momento em que "o europeu descobriu que não podia mais escrever a sua prosa do mundo sem o contributo cada vez mais avassalador da diferença aportada pelos vorazes bárbaros alexandrinos" do nosso continente. Por isso, pergunta:

\footnotetext{
${ }^{3}$ Teoria desenvolvida especialmente no ensaio "Da razão antropofágica: diálogo e diferença na cultura brasileira".
} 
Que haveria de novo, sem Borges, no nouveau roman de Robbe-Grillet? Quem poderá agora ler Proust sem admitir Lezama Lima? Ler Mallarmé, hoje, sem considerar as hipóteses intertextuais de Trilce de Vallejo e Blanco de Octavio Paz? Ou contribuir para o 'poema universal progressivo' sem redeglutir a poesia concreta brasileira do grupo Noigandres? ("Da razão ..." 261).

Sem dúvida, muitas outras perguntas como essas poderiam ser aqui formuladas. Sobretudo porque tal movimento transcultural, feito de traduções e retraduções de alteridades cada vez mais outras, atinge também as literaturas não-mediterrâneas. Como acrescenta Haroldo de Campos,

ingredientes orientais, hindus, chineses e japoneses, têm entrado no alambique 'sympoético' desses neo-alquimistas: em Tablada e Octavio Paz; nos 'senderos bifurcados'de Borges e nos ritos iniciáticos do Elizondo de Farabeuf; em Lezama e Severo Sarduy, em Oswald e na poesia concreta brasileira, por exemplo ("Da razão ...'250).

O que vem levando, cada vez mais, tanto Borges quanto Paz ou os concretos a serem traduzidos e redeglutidos em muitos países orientais.

O próprio Haroldo de Campos poderia ser inserido mais explicitamente nesse rol de autores, já que, sobretudo através do trabalho de tradução, vem há muito tempo vasculhando - sob o foco do método ideogramático de Ezra Pound - as minúcias da linguagem poética oriental, de procedências japonesa e chinesa. Com sua "mandíbula devoradora", o poeta-crítico brasileiro não cessa de explorar os recursos sonoros e visuais oferecidos tanto pela poesia clássica chinesa quanto pelo haikai e o teatro Nô japonês, com o propósito não apenas de se nutrir poeticamente - uma vez que adere à prática da metáfora ideogramática e à busca da linguagem concentrada em sua própria poesia - como também de contribuir para os novos rumos da poesia e da crítica brasileiras, por acreditar que a tradução textual interfere no fluxo da produção literária e atua incisivamente na própria história da literatura. Com isso, coloca a poesia oriental, reprocessada radicalmente através de procedimentos próprios das poéticas de ruptura, no circuito poético do Ocidente do final do século XX.

Movimento que se dá de maneira distinta na obra de Paz, uma vez que este, nutrido de um interesse que não se circunscreve apenas ao âmbito da linguagem, incorporou visceralmente o legado oriental à sua própria maneira de pensar. Tendo se confrontado diretamente - por ter vivido na Índia e ter passado uma temporada no Japão-com esse outro radical que o Oriente representa para um latino-americano já escolado no exercício da "outridade", o poeta mexicano não apenas aproveitou o legado poético dessas tradições, mas também demonstrou um profundo interesse pelos aspectos históricos, sociais e políticos de cada uma delas. Além de escrever ensaios, traduzir poemas e recriar formas poéticas oriundas dessas culturas, aproveitou muito do substrato filosófico (ou antifilosófico) das várias correntes do budismo, especialmente o tântrico, a ele somando outras aquisições intelectuais, poéticas e vivenciais. 
Como se vê, os dois poetas-críticos, na mesma proporção em que pensam a pluralidade da literatura de nosso continente, também exercem essa pluralidade, seja lendo e traduzindo outras culturas, seja compondo poemas proliferantes, de feição cosmológica, como Blanco e Galáxias. Dão, por isso mesmo, respostas críticas tanto ao logocentrismo ocidental quanto à concepção evolutivo-linear de história literária, relativizando conceitos e eliminando hierarquias culturais. Por vias dissímiles, apontam maneiras inventivas de se conceber o diálogo da América Latina com o legado europeu, ao mesmo tempo que vêem nossa cultura como ponto de confluência de espaços e temporalidades variadas. Paz, como vimos, por tomá-la, pela via analógica, como uma "ocidentalidade" paradoxal, que incorpora dinamicamente "o outro, os outros: o índio, as culturas precolombianas ou trazidas da África pelos negros, a excentricidade da herança hispano-árabe, o caráter particular de nossa história" (Paz Los signos 41-42). E Campos, por tomá-la, sob a ótica da "redevoração planetária", como um caldeirão transcultural onde coexistem ingredientes de todas as espécies e procedências.

Foi precisamente movidos por essas semelhanças e diferenças, que os dois poetas têm mantido, desde os anos 60 , um diálogo crítico-criativo de expressiva importância para que se iniciasse um intercâmbio - até então praticamente inexistente- entre México e Brasil. Como aponta Rodolfo Mata Sandoval, em estudo comparativo sobre os dois poetas-críticos, "apesar da diferença de quinze anos que os separa e que faz com que os historiadores da literatura os cataloguem como pertencentes a 'gerações' diferentes, suas trajetórias têm recebido influxos similares" (Sandoval 1). Visíveis em vários momentos da produção de um e de outro.

Compartilhando — cada um à sua maneira - um vivo interesse pela obra de Mallarmé e pelos movimentos de ruptura da modernidade, ambos iniciaram um intercâmbio quase todo centrado no debate de questões sérias sobre o fazer poético, através do qual puderam reciclar afinidades e discordâncias. O que se pode constatar na obra conjunta Transblanco, publicada por Campos em 1986 e relançada no ano de 1994 , que além de apresentar a tradução haroldiana do poema-crítico Blanco de Octavio Paz, reúne traduções de vários outros poemas, textos diversificados sobre o universo literário do poeta mexicano, além de cartas dos dois poetas-críticos.

Tais trocas intertextuais, que implicam inegavelmente uma abertura de fronteiras, não poderiam deixar, portanto, de possibilitar que o "americanismo cosmopolita" de ambos se ampliasse, já que os dois ramos (o de língua espanhola e o de língua portuguesa) da literatura latino-americana foram por eles aproximados, contrariando uma certa tendência (presente, em vários momentos, no próprio Paz) de se restringir a América Latina ao âmbito dos países de colonização hispânica.

Num momento avassalado por teorias críticas globalizadas e globalizantes, que buscam apaziguar artificialmente as diferenças e as especificidades estéticas, os dois poetas —em "conjunção galáctica", como diria Rodríguez Monegal - sustentam a pluralidade de linguagens e o diálogo criativo entre dois países de vasta diversidade cultural. Não bastasse que as suas considerações sobre a literatura latino-americana 
tenham precedido, por outros rumos, alguns aspectos das recentes teorias sobre $o$ hibridismo e a heterogeneidade de nossas culturas, eles não abrem mão da mirada crítica, desafiadora, em relação aos discursos instituídos e institucionalizados, sobretudo os que tentam fazer da literatura, da poesia, meros acontecimentos históricos, esvaziados de inventividade estética e da potencialidade (inerente a toda arte) de desconstruir, pela linguagem, realidades e contextos.

\section{OBRAS CITADAS}

Calvino, Italo. Seis propostas para o próximo milênio. 1988. São Paulo: Companhia das Letras, 1990.

Campos, Haroldo de. Metalinguagem e outras metas. São Paulo: Perspectiva, 1993. O seqüestro do barroco na formação da literatura brasileira. Salvador: Casa de Jorge Amado, 1989.

Galáxias. São Paulo: Ex-Libris, 1984.

A operação do texto. São Paulo: Perspectiva, 1976.

A arte no horizonte do provável. São Paulo: Perspectiva, 1969.

e Octavio Paz. Transblanco. 1986. São Paulo: Siciliano, 1994.

Fuentes, Carlos. "El tiempo de Octavio Paz". Octavio Paz, Los signos en rotación (1971; Madrid: Alianza Editorial, 1983) 15.

Lezama Lima, José. A dignidade da poesia. 1989. São Paulo: Ática, 1996. A expressão americana. 1957. São Paulo: Brasiliense, 1988.

Leminski, Paulo. Distraídos venceremos. São Paulo: Brasiliense, 1985.

Maciel, Maria Esther. As vertigens da lucidez: poesia e crítica em Octavio Paz.. São Paulo: Experimento, 1995.

Octavio Paz: Ruptura e Convergência. Ensaios de Semiótica 26 (Belo Horizonte, 1992-1993).

e Haroldo de Campos. Conversa sobre Octavio Paz. Nossa América 1. São Paulo: Memorial da América Latina, 1996.

Paz, Octavio. "América en plural y singular". Itinerário. México: Fondo de Cultura Económica, 1993.

“Centro móvil”. El signo y el garabato. 1973. México: Joaquín Mortiz, 1992. Hombres en su siglo. México: Seix Barral, 1990.

Pasión crítica. México: Seix Barral, 1985.

"Una forma que se busca". Corriente alterna. 1967; México: Siglo XXI, 1984. Los signos en rotacióny otros ensayos. 1971. Madrid: Alianza Editorial, 1983. "Nosotros: los otros". Vuelta 223 (1995): 12-22.

Sandoval, Rodolfo Mata. Octavio Paz e Haroldo de Campos: contradições da modernidade na América Latina. São Paulo: USP, 1993. (Dissertação de mestrado).

Sarduy, Severo. Ensaios generales sobre el barroco. México: Fondo de Cultura Econômica, 1987. 